\section{(6) OPEN ACCESS}

\title{
Home care aides' experiences of verbal abuse: a survey of characteristics and risk factors
}

\author{
Nicole D Karlsson, ${ }^{1}$ Pia K Markkanen, ${ }^{1}$ David Kriebel, ${ }^{1}$ Rebecca J Gore, ${ }^{2}$ \\ Catherine J Galligan, ${ }^{1}$ Susan R Sama, ${ }^{1}$ Margaret M Quinn ${ }^{\oplus}$
}

${ }^{1}$ Department of Public Health, University of Massachusetts, Lowell, Massachusetts, USA ${ }^{2}$ Department of Biomedical Engineering, University of Massachusetts, Lowell, Massachusetts, USA

\section{Correspondence to}

Professor Margaret M Quinn, Department of Public Health, University of Massachusetts Lowell, Lowell, MA 01854, USA; margaret_quinn@uml.edu

Received 22 November 2018 Revised 24 March 2019 Accepted 15 April 2019

\section{Check for updates}

(c) Author(s) (or their employer(s)) 2019. Re-use permitted under CC BY-NC. No commercial re-use. See rights and permissions. Published by BMJ.

To cite: Karlsson ND,

Markkanen PK, Kriebel D,

et al. Occup Environ Med

2019:76:448-454

\section{ABSTRACT}

Objective Violence from care recipients and family members, including both verbal and physical abuse, is a serious occupational hazard for healthcare and social assistance workers. Most workplace violence studies in this sector focus on hospitals and other institutional settings. This study examined verbal abuse in a large home care $(\mathrm{HC})$ aide population and evaluated risk factors.

Methods We used questionnaire survey data collected as part of a larger mixed methods study of a range of working conditions among $\mathrm{HC}$ aides. This paper focuses on survey responses of $\mathrm{HC}$ aides $(n=954)$ who reported on verbal abuse from non-family clients and their family members. Risk factors were identified in univariate and multivariable analyses.

Results Twenty-two per cent $(n=206)$ of aides reported at least one incident of verbal abuse in the 12 months before the survey. Three factors were found to be important in multivariable models: clients with dementia (relative risk (RR) 1.38, 95\% Cl 1.07 to 1.78), homes with too little space for the aide to work (RR 1.52, $95 \% \mathrm{Cl} 1.17$ to 1.97 ) and predictable work hours (RR $0.74,95 \% \mathrm{Cl} 0.58$ to 0.94 ); two additional factors were associated with verbal abuse, although not as strongly: having clients with limited mobility (RR 1.35, 95\% Cl 0.94 to 1.93) and an unclear plan for care delivery (RR $1.27,95 \% \mathrm{Cl} 0.95$ to 1.69). Aides reporting verbal abuse were 11 times as likely to also report physical abuse (RR $11.53 ; 95 \% \mathrm{Cl} 6.84$ to 19.45$)$.

Conclusions Verbal abuse is common among $\mathrm{HC}$ aides. These findings suggest specific changes in work organisation and training that may help reduce verbal abuse.

\section{BACKGROUND}

Violence is a serious occupational hazard in the US healthcare and social assistance sectors and is recognised as a problem in need of additional research and preventive interventions. ${ }^{1-10}$ The objectives of this study were to quantify the risks of verbal abuse directed at workers from clients and clients' family members in a large US population of home care $(\mathrm{HC})$ aides and to evaluate risk factors occurring at the aide, client and work-organisational levels.

For home health services, rates of workplace violence for injuries leading to days away from work as recorded by the US Bureau of Labour Statistics increased $87 \%$ from 2006 to $2016 .{ }^{11}$ While public focus is often on physical assault, healthcare and

\section{Key messages}

What is already known about this subject?

- Violent behaviours of care recipients towards healthcare workers are widespread and can lead to occupational injuries and illness, as well as job dissatisfaction and burnout.

- Studies often focus on physical assault; however, verbal abuse also causes serious psychological and physiological harm.

- Home care (HC) is a significant and rapidly growing segment of healthcare and social services with characteristics both similar to and distinct from facility-based care.

What are the new findings?

- HC aides frequently reported verbal abuse by clients and clients' family members.

- Aides caring for clients with dementia, working in a home with too little space to perform care tasks and having unpredictable work schedules were found to be risk factors for verbal abuse.

- There was suggestive evidence that unclear plans for delivering care and having clients with limited mobility were also risk factors.

- Verbal abuse was strongly associated with physical abuse.

How might this impact on policy or clinical practice in the foreseeable future?

- Verbal abuse of HC aides by clients and family members is common and approaches to reducing it should be a priority for $\mathrm{HC}$ employers.

- The study findings suggest specific factors to target with policy and training interventions.

social assistance workers may experience persistent serious health consequences from non-physical types of violence, including verbal abuse, from those to whom they are delivering care. ${ }^{12} 13$

Home-based care and services continue their rapid growth internationally. In 2016 in the USA, there were approximately 2.9 million home health and personal care aides with 1.2 million new aide jobs projected by $2026 .{ }^{14}$ There are numerous occupational titles for aides working in HC, including home health aide, certified nursing assistant, hospice aide and personal care aide. Here, we use the overarching industry term 'home care aide' to refer to the full range of occupational titles because 
there is considerable overlap in job duties. Most aides assist someone in their home with mobility and activities of daily living such as physical exercising, bathing, dressing, toileting, skin care, food preparation and house cleaning. ${ }^{15}$ In the USA, HC recipients may be called consumers, clients or patients, depending on the medical or social service system that provides their care; in this paper, 'client' refers to all care recipients. Aides mainly are hired by a private business (agency) or directly by clients or their families. The majority of $\mathrm{HC}$ aides are women, low-wage workers and increasingly racial/ethnic minorities and immigrants. ${ }^{16}$ Unlike aides in institutional settings, HC aides typically work alone. These social and work organisational factors make aides particularly vulnerable to violence.

Definitions of occupational violence vary but generally include a spectrum of physical, verbal, emotional and sexual behaviours. ${ }^{17}$ Verbal acts are described in research with varying terminology, including violence, abuse and aggression. In this study, challenging verbal behaviours by clients are referred to as abuse. The US National Institute for Occupational Safety and Health (NIOSH) defines verbally abusive behaviours as workplace violence. ${ }^{18}$

There is no gold standard measurement tool for quantitative research on occupational violence. Data from HC studies are self-reported and have a wide distribution; for example, frequency of verbal abuse among HC aides and similar jobs ranges from $26 \%$ to $65.1 \%^{2319-21}$ and of physical violence from $3.3 \%$ to $44.6 \% .^{2371921}$

This paper follows a conceptual model for the relationship between verbal and physical violence (figure 1), whereby verbal abuse may directly lead to harmful psychological outcomes and also predict physical abuse leading to physical and psychological harm. ${ }^{281922-27}$ Research suggests that verbal and physical abuse are strongly correlated in healthcare. ${ }^{25}$ Also, frequent verbal abuse may be a stronger predictor of workers' perception of safety than less frequent incidents of physical abuse. ${ }^{27}$ Although literature is limited on the potential escalation of verbal abuse to physical abuse in the workplace, it is a recognised pattern in intimate partner violence research. ${ }^{26}$ Behaviour patterns in partner violence may be relevant to $\mathrm{HC}$ because aides and clients are frequently in long-term care relationships with family like bonds described as 'fictive kinship'. ${ }^{28}$

HC workers may be especially vulnerable to impacts from verbal abuse, as the isolated nature of their jobs and requirements of client privacy leave them with fewer resources for social support that can help moderate the stress response. In HC, verbal abuse has been found to be related to negative emotional reactions; burnout, stress, sleep problems and depression. ${ }^{2} 822$ Abuse has been associated with decreased job satisfaction; and emotional hazards, including difficult, abusive clients, have been associated with increased worker turnover. ${ }^{23} 24$

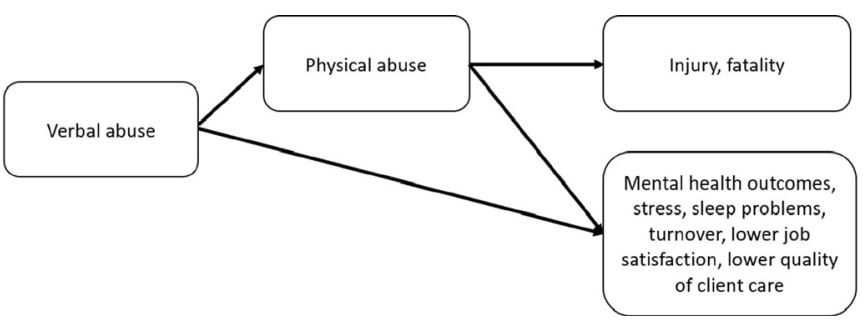

Figure 1 A conceptual model of different potential pathways from verbal abuse to harmful outcomes based on the literature.

\section{METHODS}

The source of data for this study, the Safe Home Care Survey, was a self-administered questionnaire survey completed by HC aides as part of a larger mixed methods research initiative called the Safe Home Care Project. The questionnaire and survey administration methods were grounded in a formative qualitative research phase using presurvey focus groups with aides and in-depth interviews with agency and client employers and labour representatives. ${ }^{29}$ Postsurvey focus groups and interviews also were conducted to gain insights about the survey results and possible preventive interventions (findings to be reported elsewhere). All aides gave informed consent before participation.

The survey, conducted between September 2012 and April 2013, assessed working conditions experienced in the prior 12 months. Agency-hired aides were recruited from $7 \mathrm{HC}$ agencies (16 sites) in Massachusetts, USA. Aides hired directly by HC clients or clients' families ('client-hired') were recruited via their labour union. The original survey population totalled $1249 \mathrm{HC}$ aides aged at least 18 years (634 agency-hired, 615 client-hired). The population in this study is a subset comprising $954 \mathrm{HC}$ aides who reported caring for non-family members. The study was restricted to clients who were not related to aides because the literature suggests that family caregivers may contextualise harmful behaviours differently than non-family caregivers. ${ }^{30}$ The survey design, administration, recruitment, response rates and overall findings were published previously. ${ }^{15}$ Following our previously published methods, the questionnaire was piloted among HC aides not participating in the study. ${ }^{31}$ The questionnaire survey consisted of two parts. Part 1 gathered information on individual aides ('aide-level'), such as demographics, health outcomes and general conditions of employment. Part 2 ('visit-level') gathered detailed information on work practices and home and client conditions from specific visits each aide conducted with up to five $\mathrm{HC}$ clients within the prior month. This study's HC aide population contributed reports on 3189 visits.

The survey questions and the outcome and risk factor variables were informed by the formative research phase of this study, ${ }^{29}$ 2007 National Home Health Aide Survey ${ }^{32}$ and Massachusetts Nurses Association Survey on Workplace Violence/Abuse. ${ }^{33}$ We defined the incidence of verbal abuse using response to a survey question asking whether an aide had experienced at least one incident of verbal abuse within the past 12 months from a client or client's family member. Four forms of verbal abuse were ascertained from the survey responses: 'being yelled at or spoken to in an angry or humiliating tone'; 'made to feel bad about myself'; 'racial, ethnic, religious or other personal insults' and 'verbal threat of harm'.

Aide risk factor variables were constructed from part 1 of the survey and represented demographic characteristics which might make an aide more or less vulnerable or likely to experience verbal abuse. These included age, race, ethnicity, nativity and economic vulnerability. Age was constructed as a binary variable divided at 48 years, the median age of the study population, which closely corresponded with a national HC median age of 47. ${ }^{16}$ Economic vulnerability was identified when aides reported that they worked in their current HC job because they could not find another job, and/or that they relied on it for health insurance.

Potential work-organisational risk factors included how the aide was hired (agency-hired vs client-hired), job stability (based on survey responses: "I have a stable job, and I'm not afraid of losing it") and any use of safe patient handling devices for client 
mobilisation. Having predictable work hours was indicated when aides reported that their hours were 'usually the same, week to week', whereas those reporting that their hours 'vary somewhat' or were 'highly unpredictable' were considered to have unpredictable work hours. An assessment of general safety measures on the job was derived from two questions: whether their employer provided gloves and whether they knew how to report blood exposures and injuries from medical sharps. Two additional variables were derived from visit-level data: whether, during a specific visit, the aide had the time needed to perform care tasks and whether clients had a clearly specified plan for their care (a 'care plan'). The care plan is usually developed by a case manager employed by an agency or social services to assess clients' needs for HC; it may contain instructions for the aide and for the client.

Client characteristics chosen as potential risk factors were related to client health conditions, client behaviours and home environment conditions. An aide was considered exposed if she reported the risk factor being present during at least one of the reported visits.

Log-binomial regression was used to estimate relative risks (RR) of verbal abuse within the past 12 months. After univariate modelling, confounding was investigated by multivariable modelling. Potential risk factor variables were added one at a time to the log-binomial model for risk of verbal abuse, choosing from all variables with a $\mathrm{p}$ value $<0.20$ in univariate analysis. Variables were retained in multivariable models when their $\mathrm{p}$ values were $<0.05$. Confounding was defined as a change in a coefficient of $>10 \%$. Two-way interactions among variables in the final model were investigated using product terms.

\section{RESULTS}

In total, 206 aides (22\%) reported at least one incident of verbal abuse in the 12 months prior to the survey: being yelled at or spoken to in an angry or humiliating tone (17\%); made to feel bad about myself (10\%); racial, ethnic, religious or other personal insults (6\%) and verbal threat of harm (5\%). Aides could report more than one kind of verbal abuse: among the $22 \%$ who reported any verbal abuse, 51\% experienced more than one kind and 5\% experienced all four kinds. Physical abuse was less common than verbal abuse $(7.4 \%$ vs $22 \%$, respectively); however, the two types of abuse were strongly associated. Aides who reported verbal abuse were 11 times as likely to also report physical abuse within the past 12 months as aides who did not report verbal abuse (RR $11.53 ; 95 \%$ CI 6.84 to 19.45 ). The number of physical abuse incidents was insufficient for risk factor modelling.

\section{Aide demographic characteristics}

Age was the only aide characteristic that was significantly associated with risk of verbal abuse in univariate analysis (table 1); those above the median age 48 were less likely to report having experienced verbal abuse (RR $0.59,95 \%$ CI 0.45 to 0.76 ). We further investigated effect modification and confounding by age of the work-organisational and client-related risk factors.

\section{Work-organisational risk factors}

In the univariate analysis, aides with predictable hours were less likely to report verbal abuse than those with unpredictable hours (RR $0.65,95 \%$ CI 0.51 to 0.83 ) (table 2 ). Aides hired directly by a client were somewhat less likely to report verbal abuse than those hired by agencies (RR $0.76,95 \%$ CI 0.58 to 1.00 ). The following factors were associated with increased risk of verbal
Table 1 Home care (HC) aides' demographic characteristics and univariate relative risks (RR) of reporting verbal abuse in the past 12 months, Safe Home Care Survey, Massachusetts, USA

\begin{tabular}{|c|c|c|c|c|}
\hline & \multirow[b]{2}{*}{$\begin{array}{l}\text { Number of } \\
\text { aides } \\
\text { ( } n=954)\end{array}$} & \multicolumn{3}{|c|}{ Verbal abuse in past 12 months* } \\
\hline & & $\begin{array}{l}\text { Number } \\
\text { reporting verbal } \\
\text { abuse }\end{array}$ & RR & $95 \% \mathrm{Cl}$ \\
\hline \multicolumn{5}{|l|}{ Age (years) } \\
\hline$>48$ & 455 & 72 & 0.59 & 0.45 to 0.76 \\
\hline$\leq 48 \dagger$ & 476 & 128 & & \\
\hline Missing & 23 & 6 & & \\
\hline \multicolumn{5}{|l|}{ Gender } \\
\hline Male & 93 & 19 & 0.94 & 0.62 to 1.44 \\
\hline Female† & 858 & 186 & & \\
\hline Missing & 3 & 1 & & \\
\hline \multicolumn{5}{|l|}{ Race } \\
\hline $\begin{array}{l}\text { Non-white or } \\
\text { mixed race }\end{array}$ & 399 & 80 & 0.90 & 0.69 to 1.17 \\
\hline Whitet & 431 & 96 & & \\
\hline Missing & 124 & 30 & & \\
\hline \multicolumn{5}{|l|}{ Hispanic/Latino } \\
\hline Yes & 154 & 37 & 1.11 & 0.82 to 1.52 \\
\hline Not & 760 & 164 & & \\
\hline Missing & 40 & 5 & & \\
\hline \multicolumn{5}{|l|}{$\begin{array}{l}\text { Born outside the } \\
\text { USA }\end{array}$} \\
\hline Yes & 383 & 78 & 0.91 & 0.71 to 1.17 \\
\hline Not & 566 & 127 & & \\
\hline Missing & 5 & 1 & & \\
\hline \multicolumn{5}{|l|}{$\begin{array}{l}\text { Immigrant within } \\
\text { past } 5 \text { years }\end{array}$} \\
\hline Yes & 55 & 12 & 1.01 & 0.60 to 1.69 \\
\hline Not & 892 & 193 & & \\
\hline Missing & 7 & 1 & & \\
\hline \multicolumn{5}{|c|}{$\begin{array}{l}\text { Economic } \\
\text { dependence on job }\end{array}$} \\
\hline Yes‡ & 225 & 55 & 1.18 & 0.90 to 1.55 \\
\hline Not & 729 & 151 & & \\
\hline
\end{tabular}

*Defined as at least one incident of verbal abuse in the past 12 months. tReferent.

$\ddagger$ Aides who reported that a reason they worked in their current $\mathrm{HC}$ job was because they could not find another job and/or they rely on it for health insurance.

abuse: an aide not having the time needed to perform the care work (RR $1.60,95 \%$ CI 1.17 to 2.18 ), using a client handling device (RR 1.36, 95\% CI 1.06 to 1.75 ) and not having a clear care plan (RR $1.62,95 \%$ CI 1.21 to 2.17 ).

\section{Client-related risk factors}

All of the client variables were associated with increased risk of verbal abuse in univariate analyses except not sharing a common language with the client-called language discordance (table 2). Reporting working in a home with too little space was most strongly associated with risk of verbal abuse (RR 1.92, 95\% CI 1.51 to 2.44$)$, followed by three client health conditions: having a client with limited mobility (RR 1.73 , 95\% CI 1.21 to 2.47 ), with dementia (RR $1.65,95 \%$ CI 1.29 to 2.10 ) and with mental illness or psychological issues (RR $1.58,95 \%$ CI 1.24 to 2.01). Risk of verbal abuse was also associated with having a client who smoked indoors (RR 1.29, 95\% CI 1.00 to 1.67 ). 
Table 2 Univariate models of relative risks (RR) of verbal abuse reported by home care aides in the past 12 months, by work-organisational and client-related characteristics, Safe Home Care Survey, Massachusetts, USA

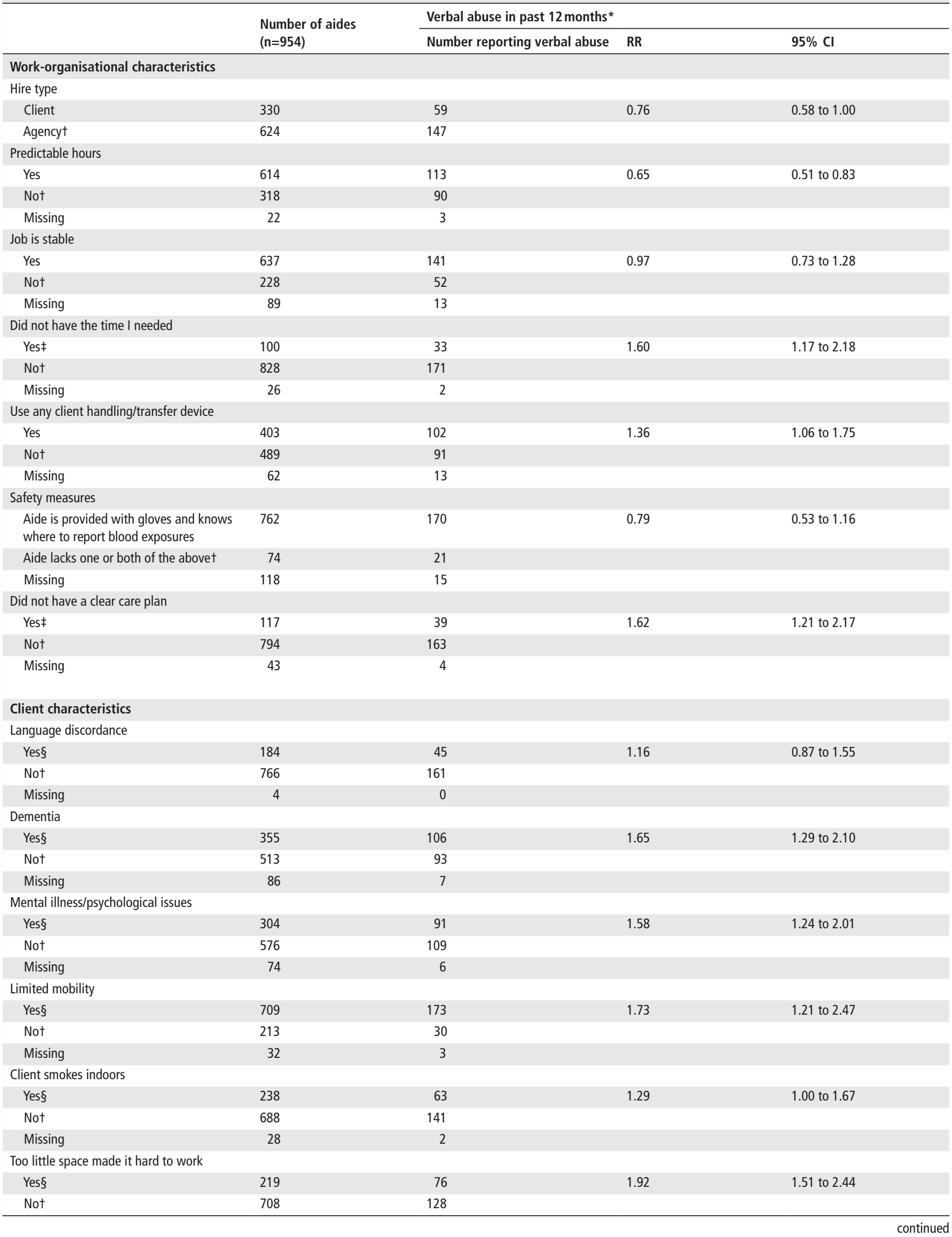


Table 2 continued

\begin{tabular}{lllll}
\hline & \multirow{2}{*}{$\begin{array}{l}\text { Number of aides } \\
(\mathbf{n}=954)\end{array}$} & Verbal abuse in past 12 months* & \\
\cline { 2 - 4 } & 27 & Number reporting verbal abuse & RR & $95 \% \mathrm{Cl}$ \\
\hline Missing & 27 & & \\
\hline
\end{tabular}

*Defined as at least one incident of verbal abuse in the past year.

tReferent.

$\ddagger$ Aides who reported this working condition during at least one recent client visit within the past month.

$\S$ Aides who reported at least one recent visit to a client with this characteristic within the past month.

\section{Multivariable model}

In the final model, five risk factors were found to be associated with verbal abuse (table 3 , model 1). Client-related factors were: having limited mobility, having dementia and too little space in the client's home for the aide to work. At the work-organisational level, having an unclear care plan was a risk factor while predictable work hours was protective. Once these factors were included in the model, there was no difference in risk of verbal abuse between those aides hired directly by clients versus those hired by agencies.

After adjusting for age, the only aide characteristic associated with verbal abuse, three work-organisational and client characteristics were significantly associated with verbal abuse: a client having dementia, too little space to work and predictable work hours (table 3, model 2). Age did not confound the association between verbal abuse and the work-organisational or client-related factors in the model. Age also did not act as an effect modifier (all interaction terms $\mathrm{p}>0.20$; data not shown).

\section{DISCUSSION}

Aides above the median age of 48 years had a reduced risk of verbal abuse, a finding also reported in another $\mathrm{HC}$ study. ${ }^{21} \mathrm{~A}$ possible explanation is that age is a proxy for job experience and that with experience comes better communication and coping skills. Additionally, our focus groups and some literature suggest that older aides may be better able to understand a client's life experiences and thus may relate better to an older client's health and emotional needs. ${ }^{28} 29$

In the age-adjusted model, two client-related factors (dementia and lack of adequate work space in a client's home) were important risk factors for verbal abuse while one work-organisational factor (an aide having predictable work hours) was

Table 3 Final models estimating the association between important risk factors and risk of reporting verbal abuse in the past 12 months, by work-organisational and client-related risk factors, Safe Home Care Survey, Massachusetts, USA

\begin{tabular}{|c|c|c|}
\hline & $\begin{array}{l}\text { Model 1: } \\
\text { RR } \\
95 \% \mathrm{Cl}\end{array}$ & $\begin{array}{l}\text { Model 2: } \\
\text { adjusted for age* } \\
\text { RR } \\
95 \% \mathrm{Cl}\end{array}$ \\
\hline \multirow[t]{2}{*}{ Client with limited mobility } & 1.47 & 1.35 \\
\hline & 1.03 to 2.10 & 0.94 to 1.93 \\
\hline \multirow[t]{2}{*}{ Client with dementia } & 1.39 & 1.38 \\
\hline & 1.08 to $1.79 d$ & 1.07 to 1.78 \\
\hline \multirow[t]{2}{*}{ Too little space to work } & 1.51 & 1.52 \\
\hline & 1.16 to 1.95 & 1.17 to 1.97 \\
\hline \multirow[t]{2}{*}{ Unclear care plan } & 1.35 & 1.27 \\
\hline & 1.01 to 1.81 & 0.95 to 1.69 \\
\hline \multirow[t]{2}{*}{ Predictable hours } & 0.73 & 0.74 \\
\hline & 0.58 to 0.94 & 0.58 to 0.94 \\
\hline
\end{tabular}

*Model includes the five variables shown, adjusted for age of aide (see text). protective. In HC, predictable hours reflect the time that an aide works and often a routine with known clients. Predictable work hours may foster relationships in which clients and aides understand each other's expectations. Routine and predictability with consistent staff may also reduce confusion and irritability in $\mathrm{HC}$ clients; this consistency is already recommended for addressing challenging behaviours of patients with dementia in long-term care. ${ }^{34}$ Our formative phase study ${ }^{29}$ also found that change is not easy for elders; the first client visit is often the hardest for aides.

Our finding that dementia is an important risk factor for verbal abuse is consistent with findings in several studies of occupational violence against health workers. ${ }^{3} 72934$ We also found that a client's home with too little space for care work was an important risk factor. While we are not aware of previous findings of inadequate work space as a factor in verbal abuse, it is consistent with literature on the importance of other aspects of good workplace environmental design for violence prevention in healthcare and social services. ${ }^{435}$

There was suggestive evidence for two additional risk factors, although their CIs included the null in the final age-adjusted model: clients with limited mobility and lack of clearly specified care plans. These findings are supported by previous research. For example, handling and transfer tasks have been identified as risks for physical abuse in HC and nursing homes, ${ }^{736}$ and it may be that the condition of having limited mobility, beyond the specific act of handling, is worth considering to reduce verbal abuse. Limited mobility represents a loss of independence and control, including greater dependence on assistance with intimate tasks, and relying on a HC aide for help in one's own home may compound these feelings.

It is reasonable to posit that lack of a clear care plan could lead to confusion about roles and expectations, and be a source of tension and ultimately verbal abuse. Having a clearly specified, written care plan was identified in presurvey focus groups as beneficial to both aide and client safety; however, the care plan can also be a point of tension between aide and client when aides are asked to perform activities outside the care plan or when clients do not cooperate to accomplish prescribed activities. ${ }^{29}$

The results of these analyses suggest several pathways for verbal abuse intervention. Job orientation and ongoing training may be useful to address the challenges of working with clients with limited mobility and dementia. ${ }^{3}{ }^{29}$ In Massachusetts, training requirements for agency-hired aides vary considerably from a few to 75 hours, depending on duties. Previous studies of HC in other states have found that agency-provided violence training varies considerably. ${ }^{121}$ At the time of this survey, client-hired aides received very little training. However, since our survey, client-hired aides began receiving union-negotiated job orientation including basic occupational safety. In our study's formative phase, HC agency representatives reported that a client intake evaluation-usually carried out by a case manager-contributes to both worker and client safety. This assessment is the foundation for care plan development and interventions to address 
the risk factors identified in this study could be included in this plan. $^{29}$

\section{Limitations}

Responses to the survey questions were self-reports. Healthcare workers contextualise abusive behaviours and may not consider them violence when attributed to causes such as client age or health conditions. ${ }^{37}$ To minimise potential under-reporting, the questionnaire presented descriptive questions of explicit actions under the domain of 'client/family behaviour'; the words violence or abuse were not used, and no attribution of intent was implied. Additionally, these questions were a small part of a larger survey of a wide range of work conditions among HC aides. For these reasons, it is unlikely that aides differed in willingness to complete the survey based on whether they experienced abuse.

Because reports of verbal abuse and working conditions were collected at one point in time, it cannot be determined if risk factors preceded abuse. Also, the survey design gathered aidelevel events like abuse 'in the past 12 months', while routine client and work organisation characteristics were gathered for specific visits within the past month. While the 12-month recall period is a standard occupational health survey time frame and was used in the US home health aide survey, ${ }^{32}$ recall of events may decrease with time, particularly for less severe types of verbal abuse. If so, our findings of the occurrence of verbal abuse are likely underestimates.

In the HC industry overall, job turnover among $\mathrm{HC}$ aides is high, with contributing factors ranging from financial and personal stressors to emotional strain and injury. ${ }^{2338} 39$ To the extent that abuse contributes to turnover, there may be selection bias in the aides who were still employed to receive this survey. Also, this study did not examine the link from incidence of abuse to harmful health outcomes. The measured outcome variable, designed to capture events, may not capture cognitive processing of those events which could either lead to, or protect from harm. ${ }^{22} 40$ The presence or absence of malice may impact the psychosocial consequences of an action. ${ }^{13}$ Thus, risk factors for behaviours that aides believe are committed with malice may be different from those understood to occur without malice, and this study could not account for that. Additionally, because abuse was operationalised as a binary variable, the frequency of different kinds of abuse was not compared. If some kinds of verbal abuse are more harmful than others or if frequency is a factor in causing harm, this binary variable may not represent the highest risk. These limitations likely contribute to an underestimation of the actual occurrence of verbal abuse in our study population, however, the risk and protective factors we identified are not likely impacted.

The agencies participating in the survey were members of the Massachusetts trade association for HC services, and many member agencies actively support worker safety and health; thus it is possible the agencies participating in this study were more diligent regarding occupational health than agencies in other states. This could contribute to an underestimation of the risk of verbal abuse. Since 2007, all publicly funded client-hired aides in Massachusetts are organised by a single labour union. The clienthired aides in this study are representative of this larger population. At the time of this survey, training for client-hired aides was minimal and so they were similar to non-unionised aides in this regard. However, the union has subsequently bargained successfully for worker safety measures including training benefits and orientation.

\section{CONCLUSIONS}

This study found that verbal abuse is common among HC aides and is strongly associated with physical abuse. We identified verbal abuse risk factors for which preventive interventions can be implemented. While the study cannot prove that these factors are causal, all suggested interventions also have benefits for improved care quality and work conditions beyond abuse prevention. Training on dementia can offer helpful work practice and communication strategies for aides. Initial and periodic client home assessments can include the determination of space requirements for care tasks and need for assistive devices to mobilise clients as well as development of care plans that consider the safety of both client and aide. While providing aides with predictable work hours can be challenging to the $\mathrm{HC}$ industry, it may benefit clients and aides, and potentially help address employee turnover, one of the industry's biggest challenges.

Acknowledgements Natalie Brouillette, Daniel Okyere and Chuan Sun are gratefully acknowledged for their participation in the Safe Home Care Survey administration and data preparation. The Safe Home Care Project research team members thank the home care aides and agencies, trade associations, labour unions, elder services professionals and other participants who contributed to this study. The authors would like to thank home care aides and other caregivers who enrich so many lives.

Contributors NDK, PKM and MMQ conceived of the study. PKM, DK, RJG, CJG, SRS and MMQ designed the questionnaire and collected the data. NDK conducted the statistical analyses with substantial contributions from DK, RJG and MMQ. NDK drafted the manuscript. All authors contributed to the interpretation of the findings and substantially commented on iterations of the manuscript. MMQ submitted the manuscript. All authors approved the final version.

Funding This publication was supported by the US National Institute for Occupational Safety and Health (NIOSH)/Centers for Disease Control and Prevention (CDC) grant numbers R01OH008229 and T01OH008424.

Disclaimer Its contents are solely the responsibility of the authors and do not necessarily represent the official views of the Centers for Disease Control and Prevention or the Department of Health and Human Services.

Competing interests None declared.

Patient consent for publication Not required.

Ethics approval All methods and materials were approved by the University of Massachusetts Lowell Institutional Review Board, Protocol Number: 10-040-QUIXPD.

Provenance and peer review Not commissioned; externally peer reviewed.

Open access This is an open access article distributed in accordance with the Creative Commons Attribution Non Commercial (CC BY-NC 4.0) license, which permits others to distribute, remix, adapt, build upon this work non-commercially, and license their derivative works on different terms, provided the original work is properly cited, appropriate credit is given, any changes made indicated, and the use is non-commercial. See: http://creativecommons.org/licenses/by-nc/4.0/.

\section{REFERENCES}

1 Gross N, Peek-Asa C, Nocera M, et al. Workplace violence prevention policies in home health and hospice care agencies. Online J Issues Nurs 2013;18:1.

2 Hanson GC, Perrin NA, Moss H, et al. Workplace violence against homecare workers and its relationship with workers health outcomes: a cross-sectional study. BMC Public Health 2015:15:11.

3 Nakaishi L, Moss H, Weinstein M, et al. Exploring workplace violence among home care workers in a consumer-driven home health care program. Workplace Health Saf 2013;61:441-50

4 Occupational Safety and Health Administration. Guidelines for preventing workplace violence for health care and social service workers. OSHA 3148-04r. Washington, DC, 2015.

5 U.S. Government Accountability Office. Additional efforts needed to help protect health care workers from workplace violence. GA0-16-11. 2016 https://www.gao. gov/products/GA0-16-11 (Accessed 20 Mar 2019).

6 Vladutiu CJ, Casteel C, Nocera M, et al. Characteristics of workplace violence prevention training and violent events among home health and hospice care providers. Am J Ind Med 2016;59:23-30. 
7 Galinsky T, Feng HA, Streit J, et al. Risk factors associated with patient assaults of home healthcare workers. Rehabil Nurs 2010:35:206-15.

8 Geiger-Brown J, Muntaner C, McPhaul K, et al. Abuse and violence during home care work as predictor of worker depression. Home Health Care Serv Q 2007:26:59-77.

9 McPhaul K, Lipscomb J, Johnson J. Assessing risk for violence on home health visits. Home Healthc Nurse 2010;28:278-89.

10 McPhaul KM, Lipscomb JA. Workplace violence in health care: recognized but not regulated. Online J Issues Nurs 2004:9:7.

$11 \mathrm{AFL}-\mathrm{ClO}$. Death on the job: The toll of neglect. A national and state-by-state profile of worker safety and health in the united states. $2018 \mathrm{https}$ ://aflcio.org/sites/default/ files/2018-04/DOTJ2018nb.pdf (Accessed 20 Mar 2019).

12 Gerberich SG, Church TR, McGovern PM, et al. An epidemiological study of the magnitude and consequences of work related violence: the Minnesota Nurses' Study. Occup Environ Med 2004;61:495-503.

13 Mayhew C, Chappell D. Workplace violence: an overview of patterns of risk and the emotional/stress consequences on targets. Int J Law Psychiatry 2007;30(4-5):327-39.

14 Bureau of Labor Statistics. Occupational outlook handbook: Home health aides and personal care aides. Washington, DC: U.S. Department of Labor, 2018.

15 Quinn MM, Markkanen PK, Galligan CJ, et al. Occupational health of home care aides: results of the safe home care survey. Occup Environ Med 2016;73:237-45.

16 Paraprofessional Healthcare Institute. U.S. Home care workers: Key facts. 2018 https:// phinational.org/resource/u-s-home-care-workers-key-facts-2018/ (Accessed 20 Mar 2019).

17 International Labour Office. Ending violence and harassment against women and men in the world of work, ilc. 107/v/1. International Labour Conference: 107th session. Geneva, Switzerland, 2017

18 National Institute for Occupational Safety and Health. NIOSH hazard review: Occupational hazards in home healthcare (no. 2010-125). U.S. Department of Health and Human Services, Centers for Disease Control and Prevention. 2010 http://www. cdc.gov/niosh/docs/2010-125/ (Accessed 20 Mar 2019).

19 Canton AN, Sherman MF, Magda LA, et al. Violence, job satisfaction, and employment intentions among home healthcare registered nurses. Home Healthc Nurse 2009:27:364-73.

20 Gershon RRM, Pogorzelska M, Qureshi KA. et alHome health care patients and safety hazards in the home: Preliminary findings. In: Henriksen K, Battles JB, Keyes MA, Grady ML, . eds. Advances in patient safety: New directions and alternative approaches (vol. 1: Assessment). Rockville (MD), 2008.

21 Ridenour ML, Hendricks S, Hartley D, et al. New Jersey Home Health Care Aides Survey Results. Home Health Care Manag Pract 2019.

22 Büssing A, Höge T. Aggression and violence against home care workers. J Occup Health Psychol 2004;9:206-19.

23 Butler SS. Exploring relationships among occupational safety, job turnover, and age among home care aides in Maine. New Solut 2018:27:501-23.
24 Delp L, Wallace SP, Geiger-Brown J, et al. Job stress and job satisfaction: home care workers in a consumer-directed model of care. Health Serv Res 2010:45:922-40.

25 Lanza ML, Zeiss RA, Rierdan J. Non-physical violence: a risk factor for physical violence in health care settings. Aaohn J 2006;54:397-402.

26 O'Leary KD. Psychological abuse: a variable deserving critical attention in domestic violence. Violence Vict 1999:14:3-23.

27 Blando JD, O'Hagan E, Casteel C, et al. Impact of hospital security programmes and workplace aggression on nurse perceptions of safety. J Nurs Manag 2013;21:491-8.

28 Stacey CL. The caring self: the work experiences of home care aides. Ithaca, NY: Cornell University Press, 2011.

29 Markkanen P, Quinn M, Galligan C, et al. Characterizing the nature of home care work and occupational hazards: a developmental intervention study. Am J Ind Med 2014:57:445-57.

30 Khan R, Rogers P. The normalization of sibling violence: does gender and personal experience of violence influence perceptions of physical assault against siblings? J Interpers Violence 2015;30:437-58

31 Markkanen P, Chalupka SM, Galligan C, et al. Studying home health care nurses and aides: research design and challenges. Journal of Research in Nursing 2008;13:480-95

32 Bercovitz A, Moss A, Sengupta M, et al. An overview of home health aides: United States, 2007. Natl Health Stat Report 2011;34:1-31.

33 Massachusetts Nurses Association. Workplace violence prevention materials booklet. 2008 http://www.massnurses.org/files/file/Health-and-Safety/Workplace-Violence/ Workplace Violence booklet.pdf (Accessed 20 Mar 2019).

34 Buhr GT, White HK. Difficult behaviors in long-term care patients with dementia. J Am Med Dir Assoc 2007;8(3 Suppl 2):e101-13.

35 McPhaul KM, London M, Murrett K, et al. Environmental evaluation for workplace violence in healthcare and social services. J Safety Res 2008;39:237-50.

36 Fitzwater EL, Gates DM. Testing an intervention to reduce assaults on nursing assistants in nursing homes: a pilot study. Geriatr Nurs 2002;23:18-23.

37 Isaksson U, Aström S, Graneheim UH. Violence in nursing homes: perceptions of female caregivers. J Clin Nurs 2008;17:1660-6.

38 Gleason H. Setting the agenda: Data driven advocacy to address home care aide policy. The Home Care Aide Foundation. 2018 http://commcorp.org/wp-content/ uploads/2018/02/Resource HCAF Setting-the-agenda-data-driven-advocacy-toaddress-home-care-aide-policy_Feb-2018.pdf (Accessed 20 Mar 2019).

39 McCaughey D, McGhan G, Kim J, et al. Workforce implications of injury among home health workers: evidence from the National Home Health Aide Survey. Gerontologist 2012:52:493-505.

40 Glomb TM, Cortina LM. The experience of victims: Using theories of traumatic and chronic stress to understand individual outcomes of workplace abuse. In: Kevin Kelloway E, ed. Handbook of workplace violence. Thousand Oaks, CA: SAGE Publications, Inc, 2006:517-34. 